\title{
A STUDY OF EVACUATION BEHAVIOR DURING EARTHQUAKES
}

\author{
C.-A. TAI ${ }^{1}$, Y.-L. LEE ${ }^{2} \&$ J.-T. YAU ${ }^{3}$ \\ ${ }^{1}$ R\&D Alternative Service Researcher, Architecture and Building Research Institute, Ministry of the Interior, Taiwan. \\ ${ }^{2}$ Professor, Department of Land Management and Development, Chang Jung Christian University, Taiwan. \\ ${ }^{3}$ Associate Research Fellow, Architecture and Building Research Institute, Ministry of the Interior, Taiwan.
}

\begin{abstract}
Earthquakes are a hazard in Taiwan and elsewhere. In 1946, for example, a Richter scale 6.1 earthquake caused 556 causalities and damaged more than 4,000 buildings in Sin-hua, Tainan City, Taiwan. This study investigates the aspects of resident preferences with respect to earthquake shelters. A questionnaire survey was designed to reflect the viewpoints of respondents in the context of earthquakes, including: (1) factors affecting evacuation behavior, (2) historical street district damage prevention and (3) analysis of evacuation choices. A logistic model for evacuation behavior in major earthquakes is presented, and its significant variables discussed in the context of future urban disaster planning.
\end{abstract}

Keywords: Evacuation behavior, logistic regression model, shelter.

\section{INTRODUCTION}

In 1999, Taiwan's 921 earthquake showed the vulnerability of urban areas to disaster. The unpredictable earthquake hazard requires the establishment of a prior comprehensive disaster plan, followed by a reactive posterior rescue plan for the maximization of resident and property safety. Recent research literature is focused on the institutional and statutory dimensions, in general, rather than a disaster, context. Although residents' viewpoints (public participation) are included in the decisionmaking process, most studies have focused on the location of obnoxious facilities. Evacuation shelter planning is considered from the supply side.

The present study aims at reflecting the viewpoints of residents using questionnaires and tries to find out: (1) the key factors affecting the behaviors of evacuation, (2) the shelters choices made by residents, (3) mechanisms of damage limitation in the historic street district, and (4) a logistic model of resident choice. Finally, the significant factors of the evacuation behavior are considered in the context of urban planning. This paper is organized into five sections. First, an introduction briefly points out the motives and objectives. Secondly, the literature is reviewed. Thirdly, the method and content of the questionnaires is explained. Fourthly, the results are analyzed and discussed, and finally, conclusions are drawn.

\section{LITERATURE REVIEW}

In consideration of the evacuation behavior, Kates [1] found that evacuation to shelters was hampered, to varying degrees, due to earthquake damage to buildings, bridges and roads destroyed after quakes. Løvås [2] discusses a variety of evacuation route selection criteria that may be applied by earthquake survivors. Lindell and Whitney [3] examined the relationships of self-reported adoption of 12 seismic hazard adjustments (pre-impact actions to reduce danger to persons and property) with respondents' demographic characteristics, perceived risk, perceived hazard knowledge, perceived protection responsibility, and perceived attributes of the hazard adjustments. Russo and Vitetta [4] research for the analysis and modeling of transportation systems in emergency conditions requires further studies in supply, demand, supply-demand interaction and design. In emergency conditions, there is the need to develop new methods and rearrange standard procedures. 
Kimura et al. [5] considered the evacuation behavior and found that following shocks over 6.7 on the Richter scale, $30 \%$ people decided to evacuate to designated shelters. Lee et al. [6] applying Logistic Regression Model found that evacuation transportation planning, education level and residence years significantly influence the evacuation decision of residents. Tai et al. [7] explained four possible actions relating to the spatial decision concerning disaster prevention. (i) Shelters help reduce risks and meet evacuation needs. (ii) And (iii) Disaster prevention provides an efficient way to meet both requirements. (iv) Providing disaster prevention information can remind people about disaster preparedness. Anastassiadis and Argyroudis [8] urban vulnerability assessment of elements at risk is performed through a value analysis approach based on appropriate indicators such as population, residential and trade densities, radiance and others, while a pilot application is made for Thessaloniki. The vulnerability of road network is also examined based on the interaction between collapse patterns of adjacent buildings and network functionality.

Ayis et al. [9] selected 999 people over 65 for a study of the mobility of the aged and found lower mobility and poor perceived health. Mobility was significantly (and negatively) related to age, over 70. Yi and Özadmar [10] pointed out that logistic, and especially route planning, was critical for earthquake contingency planning. Ho et al. [11] findings are: (1) the victims and the general public are concerned about the different potential hazards that might affect their residential area, (2) the negative associations between the sense of controllability and the perceived impact is high for landslide victims, but not for flood victims, and (3) disaster type, gender, and previously experienced disasters are good predictors of victims' attitudes toward natural disasters.

In a review of empirical work, Perry [12] suggested that individuals assessed personal risk by examining the proximity, certainty, and severity of the threat. In general, shelter choice was related to distance from the victims residences. Chien et al. [13] found most people first selected schools, then parks, and green field locations. However, factors influencing evacuation were numerous, including physical environmental characteristics, familiarity, accessibility, habit, and safety considerations. This study reviews the factors influencing evacuation and applies a questionnaire to determine their perceived relative importance for the purpose of evacuation modeling.

\section{METHOD}

The questionnaire is divided into three parts: (1) factors effecting evacuation of residents; (2) evaluation of historic street district; and (3) evacuation intentions. An objective evaluation equation based on binary logistic regression is used to model the evacuation behavior of residents.

\subsection{Logistic regression model}

James and Johnson [14] applied a Logistic Regression Model to evacuation from near a nuclear power plant and found the probability of an individual evacuating is related to distance from the power plant, age, perceived risks to the household, and the perceived safety of the power plant. Socioeconomic variables were insignificant. Riad et al. [15] found that previous experience or training in evacuation procedures was the most significantly related to evacuation, followed by gender, perceived risk, home ownership, income, education, children, the actions of neighbors, and previous disaster experience.

Assuming residents' decision to evacuate is a conditional probability $P\left(y=1 \mid x_{\mathrm{i}}\right)=p_{i}$. Equation (1) gives the probability that residents will evacuate, and eqn (2) the probability that they will not. Equation (3) represents the ratio of eqns (1) and (2). Equation (4) is the natural log of eqn (3), i.e. logit type of the results. 


$$
\begin{aligned}
& p_{i}= \frac{1}{1+e^{-\left(\alpha+\beta x_{i}\right)}}=\frac{e^{\alpha+\beta x_{i}}}{1+e^{a+\beta x_{i}}} \\
& 1-p_{i}=1-\left\{\frac{e^{\alpha+\beta x_{i}}}{1+e^{a+\beta x_{i}}}\right\}=\frac{1}{1+e^{a+\beta x_{i}}} \\
& \frac{p_{i}}{1-p_{i}}=e^{\left(\alpha+\beta x_{i}\right)} \\
& \ln \left[\frac{p_{i}}{1-p_{i}}\right]=\alpha+\beta x_{i}
\end{aligned}
$$

where $p_{i}$ is the probability of residents' evacuation, $x_{i}$ the independent variables, all variables affecting the evacuation behavior, $\alpha$ the intercept, $\beta$ the regression coefficients and $e$ the residuals.

\subsection{Questionnaire surveying}

At the end of May 2006, there were 10 wards in Sin-hua urban planning area with 23,330 residents in 7,298 households. Equation (5) was used for samples of 385 under $95 \%$ confidence interval.

$$
n=p(1-p) \times(Z / E)^{2}
$$

where $n$ is the sample size, $p$ the ratio of samples, $Z$ the $95 \%$ confidence interval and $E$ the maximal error tolerance.

The field survey was conducted in September 14-18, 2006. Trained interviewers visited each ward using a random sampling regime of an intensity determined by the relative population density of the wards. Four hundred questionnaires were issued, with 387 effective samples (excluding 13 with conflicting missing or undecided responses). Field sampling involved starting from a street corner and walking in an anti-clockwise direction, knocking on doors asking for interview, and repeating until the necessary sample size was obtained.

\section{RESULTS}

\subsection{Descriptive statistic results}

\subsubsection{Social-economic analysis}

The social-economic descriptive analysis results are shown in Table 1 and are summarized below:

1. The ratio of male to female was 4:6: $41.9 \%$ male (162) and $58.1 \%$ female (225).

2. $70.6 \%(22.5 \%+27.4 \%+20.7 \%)$ of the samples were between 21 and 50 , with only $15.7 \%$ over $51(11.6 \%+2.8 \%+1.3 \%)$. Most of the respondents were young adults.

3. $43.7 \%$ (169) of the samples were high school, and $34.6 \%$ (134), college graduates. In general, the respondents were educated and could receive information from news.

4. The households were divided into those (1) with children age $<12$, (2) with elders age $>65$, (3) both of (1) and (2), and (4) other. Groups (1), (2), and (3) are identified as vulnerable in evacuations. $64.8 \%(28.7 \%+18.3 \%+17.8 \%)$ of households were in this group, and the special requirements of such households should be allowed for evacuation planning. 
Table 1: Social-economic description.

\begin{tabular}{|c|c|c|c|c|c|c|c|}
\hline Items & Variables & Samples & $\%$ & Items & Variables & Samples & $\%$ \\
\hline \multirow[t]{5}{*}{ Gender } & Male & 162 & 41.9 & \multirow{5}{*}{ Education } & Elementary & 23 & 5.9 \\
\hline & Female & 225 & 58.1 & & Junior high & 53 & 13.7 \\
\hline & $<20$ & 53 & 13.7 & & Senior high & 169 & 43.7 \\
\hline & $21 \sim 30$ & 87 & 22.5 & & College & 134 & 34.6 \\
\hline & $31 \sim 40$ & 106 & 27.4 & & Graduate & 8 & 2.1 \\
\hline \multirow[t]{4}{*}{ Age } & $41 \sim 50$ & 80 & 20.7 & \multirow{4}{*}{ Household } & $<12^{1}$ & 111 & 28.7 \\
\hline & $51 \sim 60$ & 45 & 11.6 & & $>65^{2}$ & 71 & 18.3 \\
\hline & $61 \sim 70$ & 11 & 2.8 & & Both of 1 and 2 & 69 & 17.8 \\
\hline & $>71$ & 5 & 1.3 & & Other & 136 & 35.2 \\
\hline
\end{tabular}

Table 2: Residents decide NOT to evacuate.

\begin{tabular}{lccccc}
\hline Reasons & Samples & \multicolumn{1}{c}{$\%$} & Reasons & Samples & $\%$ \\
\hline Nowhere to go & 45 & 11.7 & Safer to stay than leave & 148 & 38.2 \\
Without vehicles & 9 & 2.3 & No idea but stay in house & 55 & 14.2 \\
Difficult links outside & 8 & 2.1 & Dangers for moving & 60 & 15.5 \\
Living inconvenience & 48 & 12.4 & Others & 14 & 3.6 \\
\hline
\end{tabular}

\subsubsection{Factors affecting evacuation}

Considering the factors affecting residents decide Not to evacuate, Table 2 shows the highest ratio (38.2\%) appeared in 'Safer to stay than leave'. The basic idea is that the home forms the base for living. In case of danger, people would rather to stay put. However, outside the house the uncertainty of the environment after the disaster would deter the residents from remaining in the house.

Secondly, 'Danger for movement' showed the unpredictable outcome after hazard people rationally consider the situation to make a good choice between stay or to leave. In general, we found some people think the instantaneous event of earthquake and react naturally without advance considerations.

Considering the factors affecting the potential decision of residents to evacuate, Table 3 shows the most important reason appeared as 'House collapsed'. 'Road link collapsed' showed the lowest rating. It represented the uncertainty of the transportation conditions and, therefore, had an ambivalent or negative influence on resident's decision to evacuate.

Of the Preferred choices for shelter, referred in Table 4, the most important was 'Nearest house'. It was clear that residents preferred to evacuate to locations as close as possible to their houses. The lowest important item was 'Enough lighting services' in the night. It appeared people would easily survive without lighting compared with other services.

\subsubsection{Shelter choice}

The result in Table 5 for shelter choice by residents depicted 'School' $49.4 \%$ where there were open spaces of greens and fields, and the classroom and activity center could offer temporary accommodation after a quake. However, constructional resilience of the classroom and resistance to earthquakes was required for the construction due to the public safety. 
Table 3: Residents decide to evacuate from normal location.

\begin{tabular}{lcccc}
\hline Reasons & Samples & Average & Order & $\begin{array}{c}\text { Standard } \\
\text { deviation }\end{array}$ \\
\hline House collapsed & 387 & 4.00 & 1 & 1.18 \\
Road links collapsed & 387 & 2.15 & 4 & 1.12 \\
Damage and danger on site & 387 & 3.19 & 2 & 1.19 \\
$\begin{array}{l}\text { Building services collapsed and } \\
\text { not functioning }\end{array}$ & 387 & 2.28 & 3 & 1.21 \\
\hline
\end{tabular}

Average represents the Likert 5-point scale. 5 meant the strongest intention.

Table 4: Preferred choices for shelter.

\begin{tabular}{lcccc}
\hline Reasons & Samples & Average & Order & $\begin{array}{c}\text { Standard } \\
\text { deviation }\end{array}$ \\
\hline Nearest house & 387 & 3.60 & 1 & 1.12 \\
Familiarity of the surroundings & 387 & 3.54 & 2 & 1.19 \\
Enough lighting services & 387 & 2.32 & 4 & 1.21 \\
Convenient living facilities & 387 & 3.27 & 3 & 1.45 \\
\hline
\end{tabular}

Average represents the Likert 5-point scale. 5 meant the strongest intention.

Table 5: Shelters choice by residents.

\begin{tabular}{lccccr}
\hline Items & Samples & $\%$ & Items & Samples & \multicolumn{1}{c}{$\%$} \\
\hline School & 191 & 49.4 & Green field & 92 & 23.3 \\
Park & 53 & 13.7 & Parking lot & 17 & 4.4 \\
Sports field & 34 & 8.8 & Amount & 387 & 100.0 \\
\hline
\end{tabular}

Parks and green fields comprised $37 \%(13.7 \%+23.3 \%)$ of choices due to the selection of open spaces for evacuation. However, in the 1980 periodic review of urban plan, 10.25 hectares of parkland and 0.11 hectares of green fields were rezoned for residential use with additional permissions when developed with public services supplied (see Fig. 1). Suitable areas for evacuation shelters were therefore in short supply due to residential development.

\subsubsection{Historic street district evaluation}

When we asked about the importance of historic street conservation, people concerned about the potential risk of the quake attack and endangerment of historic asset.

Table 6 shows $59.2 \%(14.2 \%+45 \%)$ people (non-residents) are very concerned about the possibility of serious damage. The historic street with a Baroque architectural style was constructed in the Japanese colonial era (1925). It had been a historical landmark and common memory. However, the vulnerable structures were not safe in an earthquake and could danger life. $10.1 \%(8.3 \%+1.8 \%)$ non-residents expressed less concern about the fate of the street. 


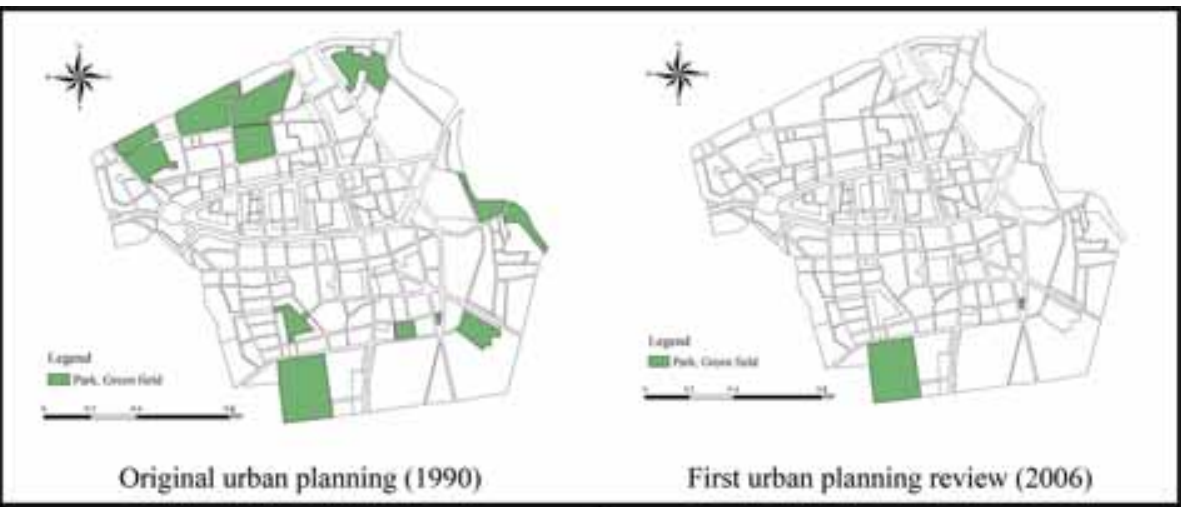

Figure 1: Park and green field location diagram.

Table 6: Concern about potential destruction of the historic street district by earthquake.

\begin{tabular}{lcc}
\hline Items - level of concern & Samples & $\%$ \\
\hline Very concerned & 55 & 14.2 \\
Concerned & 174 & 45.0 \\
Medium concern & 119 & 30.7 \\
Less concern & 32 & 8.3 \\
Not concerned & 7 & 1.8 \\
Amount & 387 & 100.0 \\
\hline
\end{tabular}

Table 7: Support for rebuilding historic street for the safety of residents.

\begin{tabular}{lcc}
\hline Items & Samples & $\%$ \\
\hline Strongly agree & 73 & 18.9 \\
Agree & 169 & 43.6 \\
Neither agree nor disagree & 90 & 23.3 \\
Disagree & 40 & 10.3 \\
Strongly disagree & 15 & 3.9 \\
Amount & 387 & 100.0 \\
\hline
\end{tabular}

In the following, the results of Table 7 represent resident attitudes about the idea of rebuilding the street to be earthquake resistant. There were $62.5 \%(18.9 \%+43.6 \%)$ of residents strongly supporting rebuilding this street to reflect concern about the safety of life and property. However, there were also $14.2 \%(10.3 \%+3.9 \%)$ who disagreed and strongly disagreed considering this cultural asset and the meaning of this historic development for the next generation.

In Table 8, 60.4\% $(19.1 \%+41.3 \%)$ agreed with the widening road width of historic street district disaster for prevention. The main reason reflected the serious possibility that the $4-\mathrm{m}$ width would 
Table 8: Widen road width in historic street district for disaster prevention.

\begin{tabular}{lcc}
\hline Items & Samples & $\%$ \\
\hline Agree very much & 74 & 19.1 \\
Agree & 160 & 41.3 \\
Neither agree nor disagree & 97 & 25.1 \\
Disagree & 51 & 13.2 \\
Disagree very much & 5 & 1.3 \\
Amount & 387 & 100.0 \\
\hline
\end{tabular}

Table 9: Evacuation intention of residents.

\begin{tabular}{lccccc}
\hline & Scale & Samples & $\%$ & Analogy to Likert scale & $\%$ \\
\hline \multirow{4}{*}{ Low } & 1 & 25 & 6.5 & Very low & 8.6 \\
& 2 & 8 & 2.1 & & \\
& 3 & 22 & 5.7 & Low & 11.4 \\
\multirow{5}{*}{ Intention } & 4 & 22 & 5.7 & & \\
& 5 & 67 & 17.3 & Medium & 28.4 \\
& 6 & 43 & 11.1 & & 27.1 \\
\multirow{4}{*}{ High } & 7 & 46 & 11.9 & High & \\
& 8 & 59 & 15.2 & & 24.5 \\
\hline
\end{tabular}

result in lane blockage after a quake. However, there were $14.5 \%(13.2 \%+1.3 \%)$ who disagreed due to the historic asset preservation considerations, and the complexity of the land ownership.

\subsubsection{Intention of residents to evacuate}

It had been more than 50 years since the 1946 earthquake. Most of the interview subjects did not have Richter scale more than 7.0 earthquake evacuation experiences. Therefore, the questionnaire design assumed an imaginary scenario comparable to the 921 earthquake (2494 fatalities, 105,480 buildings collapsed). The results in Table 9 show $51.6 \%(27.1 \%+24.5 \%)$ respondents expressed strong intention to evacuate. $20 \%(8.6 \%+11.4 \%)$ had low and very low intention to evacuate. Disaster experiences were highly related to evacuation intention.

Next, the location of those subjects $(8.6 \%+11.4 \%)$ who showed low and very low intention to evacuate was displayed ( $\boldsymbol{\Delta}$ ) using Arc GIS 10 overlayered with the location of those subject groups classified as vulnerable during evacuation ( $\bullet$ ). Figure 2 shows the overlap of $\boldsymbol{\Delta}$ and $\bullet$. Most of the respondents with intention to evacuate were co-located with evacuation-vulnerable groups. The results represented the subject's intuitive response to the dangers of earthquakes and the risks of evacuation. When facing an unexpected hazard, people were apparently very influenced by the difficulty of movement with the aged and children, and might give it more weight than unknown dangers. 


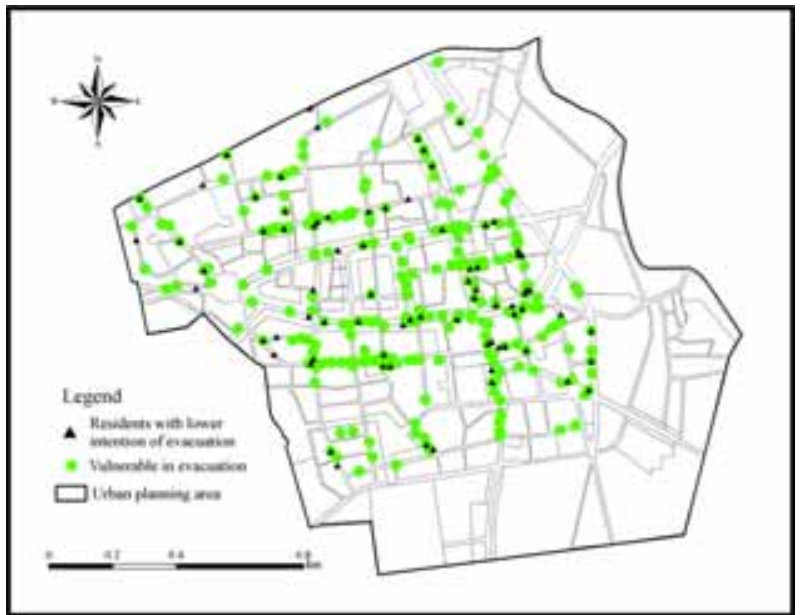

Figure 2: Overlapping of low evacuation intention and evacuation weakness.

\subsection{Logistic regression model of evacuation}

\subsubsection{Variable selection}

\subsubsection{Dependent variable}

To predict evacuation choice behavior K means clustering was applied and the samples were categorized as evacuation intention high and low. The two categories of evacuation intention were used as the dependent variables for the choice model.

\subsubsection{Factors affecting resident's evacuation choice}

a. House collapsed $\left(\mathrm{X}_{1}\right)$ : after a quake serious damage to the house will push people to evacuate. The expected sign is ' + '.

b. Road link collapsed $\left(\mathrm{X}_{2}\right)$ : after a quake serious damage to road links will push people to evacuate. The expected sign is ' + '.

c. Damage and danger on site $\left(\mathrm{X}_{3}\right)$ : after a quake serious damage and danger on site will push people to evacuate. The expected sign is ' + '.

d. Utilities not functioning $\left(\mathrm{X}_{4}\right)$ : after a quake serious failure of utilities will push people to evacuate. The expected sign is ' + '.

\subsubsection{Affecting factors of shelters' choices}

a. Familiarity of the surroundings $\left(\mathrm{X}_{5}\right)$ : after a quake, familiarity of the shelter surroundings will pull people to evacuate. The expected sign is ' + '.

b. Convenient living facilities $\left(\mathrm{X}_{6}\right)$ : after a quake, convenient living facilities will pull people to evacuate. The expected sign is ' + '.

\subsubsection{Estimation of the model}

This study used the maximum likelihood method, HL index and precision rate to evaluate model fitness. In addition, the Wald Chi-square test was used with odds to explain significant variable results. 


\subsubsection{Coefficient estimation}

The results of Wald estimation showed that variables $\mathrm{X}_{1}, \mathrm{X}_{2}, \mathrm{X}_{3}, \mathrm{X}_{4}$, and $\mathrm{X}_{6}$ significant.

\subsubsection{Model estimation}

Table 10 explains the model estimation results. Maximum likelihood (-2LL) was 90.084, Cox \& Snell $R^{2}$ was $67.8 \%$; the model explained $67.8 \%$ of the observed variation. The HL index was 7.177 and significance was $0.518(>0.05)$. The regression results could explain the dependent variable and the predicted probability was $95.9 \%$.

\subsubsection{Significant variables}

a. House collapsed $\left(\mathrm{X}_{1}\right)$

The result coefficient was $4.925>0$, significant in $99 \%$ confidence interval with expected sign. This variable explained more serious of the house collapsed and residents would express higher intention to evacuate. Moreover, the model showed house collapsed residents intention to evacuate 137 times than not in terms of odd ratio.

b. Road link collapsed $\left(\mathrm{X}_{2}\right)$

The result coefficient was $4.836>0$, significant in $99 \%$ confidence interval with expected sign. This variable explained more serious of the road link collapsed and residents would express higher intention to evacuate. Moreover, the model showed house collapsed residents intention to evacuate 125 times than not in terms of odd ratio.

c. Damaged and danger on site $\left(\mathrm{X}_{3}\right)$

The result coefficient was $5.878>0$, significant in $99 \%$ confidence interval with expected sign. This variable explained more serious of damaged and danger on site and residents would express higher intention to evacuate. Moreover, the model showed house collapsed residents intention to evacuate 356 times than not in terms of odd ratio.

d. Utilities not functioning $\left(\mathrm{X}_{4}\right)$

The result coefficient was $4.567>0$, significant in $99 \%$ confidence interval with expected sign. This variable explained more serious of life line collapsed and not functioning and residents

Table 10: Logistic regressing analysis results.

\begin{tabular}{lccccc}
\hline Independent variables & $B$ & SE & Wald & $p$ & Odds \\
\hline House collapsed $\left(\mathrm{X}_{1}\right)$ & 4.925 & 0.774 & 40.436 & $0.000^{*}$ & 137.671 \\
Road link collapsed $\left(\mathrm{X}_{2}\right)$ & 4.836 & 0.777 & 38.769 & $0.000^{*}$ & 125.908 \\
Damage and danger on site $\left(\mathrm{X}_{3}\right)$ & 5.878 & 0.879 & 44.734 & $0.000^{*}$ & 356.975 \\
Building services collapsed and not & 4.567 & 0.730 & 39.171 & $0.000^{*}$ & 96.213 \\
functioning $\left(\mathrm{X}_{4}\right)$ & & & & & \\
Familiarity of the surroundings $\left(\mathrm{X}_{5}\right)$ & -0.142 & 0.286 & 0.248 & 0.618 & 0.867 \\
Convenient living facilities $\left(\mathrm{X}_{6}\right)$ & -1.104 & 0.311 & 12.643 & $0.000^{*}$ & 0.331 \\
Constant $(a)$ & 55.841 & 8.566 & 42.500 & $0.000^{*}$ & 0.000 \\
-2 Log-likelihood (-2LL): 90.084. & & & & & \\
Cox and Snell $R^{2}$ : 0.678 & & & & & \\
HL index estimate: 7.177 , degree of freedom: 8, significance: 0.518 & & & \\
Predicted probability $(\%): 95.9$ & & & & &
\end{tabular}

$* 99 \%$ significant level. 
would express higher intention to evacuate. Moreover, the model showed house collapsed residents intention to evacuate 96 times than not in terms of odd ratio.

e. Convenient living facilities $\left(\mathrm{X}_{6}\right)$

The result coefficient was $-1.104<0,99 \%$ confidence interval with an unexpected sign. More convenient living facilities were associated with a lower expressed intention to evacuate. The result was not expected. Convenient living facilities are apparently not critical for residents to evacuate, but the facilities must still be adequate for people to stay temporarily.

\subsubsection{Insignificant variables}

Familiarity of the surroundings $\left(X_{5}\right)$ showed a coefficient of $-0.142<0$, insignificant at the $99 \%$ confidence interval with an unexpected sign. A possible reason was residents could not decide if the shelter was familiar or not. After an earthquake conditions became abnormal. In such a time of uncertainty, a lack of information may prevent people from taking many criteria, including this one, into consideration.

The Logistic Regression Model results could explain the dependent variable and the predicted probability was $95.9 \%$. Additional analysis results showed that $\mathrm{X}_{1}, \mathrm{X}_{2}, \mathrm{X}_{3}, \mathrm{X}_{4}$ and $\mathrm{X}_{6}$ significantly affect the choice of evacuation. 'House collapsed' promoted evacuation. 'Road link collapsed' represented uncertain transportation conditions and difficulty for residents to make decision. 'Damage and danger on site' and 'Utilities not functioning' both promoted evacuation, while 'Convenient living facilities' in shelters showed that such facilities were necessary and aid to the evacuees but not critical in terms of survival.

\section{CONCLUSIONS}

The behavior and choices of urban residents must be an important component in urban disaster planning, which aims to secure life and property. Faced with an unexpected natural or human hazard, past disaster experiences could give a basis for planning rules. We found that there were about $64.8 \%$ household with (1) children aged $<12$, (2) elders age $>65$ and (3) both of (1) and (2). These groups would be vulnerable and difficult to evacuate during a disaster. As populations age, there disaster planning will have to accommodate more aged people with lower personal mobility.

Finally, logistic regression choice model showed that $\mathrm{X}_{1}, \mathrm{X}_{2}, \mathrm{X}_{3}, \mathrm{X}_{4}$ and $\mathrm{X}_{6}$ had significant effect on evacuation decisions. The variables in terms of house collapsed, road link collapsed, damage and danger on site, building services collapsed and not functioning should be seriously considered in contingency planning for the aftermath of an earthquake. However, convenient living facilities were not considered important by residents. Most people regard earthquake disaster as a low probability event, and tend not to think about it, which can increase the unpredictability of the impact. Further study is therefore urged to promote resident and community empowerment for disaster preparedness. A localized plan could limit the initial disaster impact and reduce the damage.

\section{ACKNOWLEDGEMENT}

This study is supported by a grant from the National Science Council (NSC 102-2410-H-309-016), Taiwan, ROC.

\section{REFERENCES}

[1] Kates, R., Natural hazard in human ecological perspective: hypotheses and models. Economic Geography, 47(3), pp. 438-451, 1971. doi: http://dx.doi.org/10.2307/142820

[2] Løvås, G.G., Models of way finding in emergency evacuations. European Journal of Operational Research, 105(3), pp. 371-389, 1998. doi: http://dx.doi.org/10.1016/s0377-2217(97)00084-2 
[3] Lindell, M.K. \& Whitney, D.J., Correlates of household seismic hazard adjustment adoption. Risk Analysis, 20(1), pp. 13-25, 2000. doi: http://dx.doi.org/10.1111/0272-4332.00002

[4] Russo, F. \& Vitetta, A., Risk evaluation in a transportation system. Sustainable Development and Planning, 1(2), pp. 170-191, 2006. doi: http://dx.doi.org/10.2495/sdp-v1-n2-170-191

[5] Kimura, R., Hayashi, H., Tatsuki, S. \& Tamura, K., Development of the method of estimating the number of people at evacuation center in case of urban earthquake disaster, 13th World Conference on Earthquake Engineering, Vancouver, Paper No. 1306, 2004.

[6] Lee, Y.L., Ho, M.C. \& Tai, C.A., Factors influencing residents' evacuation behaviors with earthquake disaster scenario - Yung-Kang city case study. Journal of Architecture, 65, pp. 27-44, 2008.

[7] Tai, C.A., Lee, Y.L. \& Lin, C.Y., Urban disaster prevention shelter location and evacuation behavior analysis. Journal of Asian Architecture and Building Engineering, 9(1), pp. 215-220, 2010. doi: http://dx.doi.org/10.3130/jaabe.9.215

[8] Anastassiadis, A.J. \& Argyroudis, S.A., Seismic vulnerability analysis in urban systems and road networks. Application to the City of Thessaloniki, Greece. Sustainable Development and Planning, 2(3), pp. 287-301, 2007. doi: http://dx.doi.org/10.2495/sdp-v2-n3-287-301

[9] Ayis, S., Gooberman-Hill, R., Bowling, A. \& Ebrahim, S., Predicting catastrophic decline in mobility among older people. Oxford University Press on behalf of the British Geriatrics Society, 35(4), pp. 382-387, 2006.

[10] Yi, W. \& Özadmar, L., A dynamic coordination model for evacuation and support in disaster response activities. European Journal of Operational Research, 179(3), pp. 1177-1193, 2007. doi: http://dx.doi.org/10.1016/j.ejor.2005.03.077

[11] Ho, M.C., Shaw, D., Lin, S.Y., \& Chiu, Y.C., How do disaster characteristics influence risk perception? Risk Analysis, 28(3), pp. 635-643, 2008. doi: http://dx.doi.org/10.1111/j.15396924.2008.01040.x

[12] Perry, R.W., Evacuation decision-making in natural disasters. Mass Emergencies, 4(1), pp. 25-38, 1979.

[13] Chien, S.W., Chen, L.C., Chang, S.Y. \& Chiu, G.H., Development of after earthquake disaster shelter evaluation model. Journal of the Chinese Institute of Engineers, 25(5), pp. 591-596, 2002. doi: http://dx.doi.org/10.1080/02533839.2002.9670733

[14] James, H. \& Johnson, J., Predicting nuclear reactor emergency evacuation behavior. Energy, 11(9), pp. 861-868, 1986. doi: http://dx.doi.org/10.1016/0360-5442(86)90004-6

[15] Riad, J.K., Nooris, F.H. \& Ruback, B.R., Predicting evacuation in two major disasters: risk perception, social influence, and access to resources. Journal of Applied Social Psychology, 29(5), pp. 918-934, 1999. doi: http://dx.doi.org/10.1111/j.1559-1816.1999.tb00132.x 